\title{
Politique
}

Politique

\section{Getting Elected in Canada; A Political Insider Demystifies the Canadian Election Process de Tom Brook, Stratford, The Mercury Press, 1991, 253 p.}

\section{André Turcotte}

Numéro 22, automne 1992

URI : https://id.erudit.org/iderudit/040740ar

DOI : https://doi.org/10.7202/040740ar

Aller au sommaire du numéro

Éditeur(s)

Société québécoise de science politique

ISSN

0711-608X (imprimé)

1918-6584 (numérique)

Découvrir la revue

Citer ce compte rendu

Turcotte, A. (1992). Compte rendu de [Getting Elected in Canada; A Political Insider Demystifies the Canadian Election Process de Tom Brook, Stratford, The Mercury Press, 1991, 253 p.] Politique, (22), 163-165.

https://doi.org/10.7202/040740ar d'utilisation que vous pouvez consulter en ligne.

https://apropos.erudit.org/fr/usagers/politique-dutilisation/ 


\section{Getting Elected in Canada; A Political Insider Demystifies the Canadian Election Process \\ de Tom Brook, Stratford, The Mercury Press, 1991, 253 pages.}

Les premières études sur le comportement électoral au Canada accordaient une certaine importance aux candidats dans la dynamique d'une élection. Cependant, les successeurs de John Meisel, Peter Regenstreif et Mildred Schwartz se sont surtout concentrés sur l'impact des chefs de partis et des débats politiques au niveau national. Pourtant, le sort en est jeté lorsque les électeurs et électrices votent pour leur candidat local. Tom Brook s'intéresse à ces individus qui sont souvent ignorés dans la litterrature sur les élections.

Ce livre se veut un exposé sur les diverses phases d'une campagne électorale au niveau d'une circonscription, vues par un vétéran de plus de soixante-dix élections. L'auteur nous présente les différentes étapes à franchir à partir de la décision de se présenter comme candidat ou candidate jusqu'au moment où le temps est venu de se retirer. Le lecteur est initié aux aspects stratégiques de la soirée de nomination, l'importance de la période pré-électorale, le recrutement des volontaires et la préparation des discours. De plus, Tom Brook explique en détail comment mettre sur pied une campagne de financement et organiser une publicité locale qui complétera celle développée par les stratèges du parti. L'auteur considère l'impact de la vie politique sur la famille des 
candidat(e)s et les particularités d'une campagne électorale ayant une femme comme candidate. Finalement, Brook maintient qu'une des qualités les plus importantes pour un(e) candidat(e) dans les années 90, est la capacité d'admettre ses erreurs et d'être honnête avec l'électorat en ne promettant que ce qui peut être réalisé.

Ce volume a plusieurs points forts. En plus de s'attarder sur un sujet généralement négligé, le fait que Brook ait des liens avec le Nouveau Parti démocratique démontre que l'idéologie a peu d'importance lorsque le but ultime est de faire en sorte que le plus grand nombre de supporters identifiés exercent leur droit de vote. Lorsque l'auteur soutient qu'il n'y a pas de place pour la démocratie dans l'organisation d'une campagne, qu'il est souvent préférable d'éviter les débats entre candidats ou encore que tout(e) candidat(e) élu(e) se doit de penser à sa rélection le premier jour après sa victoire, on ne croirait pas que ce dernier organise des campagnes électorales pour le parti qui prône l'intégrité. Mais ce livre se veut plus qu'un exposé sinistre sur la politique locale.

Au moment où il est à la mode de critiquer nos politiciens, Tom Brook nous rappelle ce qu'une élection doit être. II avoue que le cynisme de l'électorat est probablement justifié mais l'auteur espère qu'une meilleure connaissance des réalités entourant l'élection de nos députés contribuera à modifier notre perception du monde politique. Et à plusieurs égards, il réussit. II est utile de se rappeler que derrière les réflecteurs, les bannières et messages publicitaires, des centaines d'individus offrent à leurs concitoyens de les représenter. La plupart essuieront la défaite et la majorité des vainqueurs n'aspireront à rien d'autre que les arrière-bans. Toutefois, notre système de représentation repose sur leur participation. L'auteur est particulièrement efficace lorsqu'il utilise des anecdotes et son expérience personnelle pour présenter le côté humain de la politique locale. Voter pour un candidat est le seul acte politique qu'effectue la majorité des Canadiens. En fait, même si environ 75 pour cent votent, seulement un Canadien sur quatre discute de politique et trois pour cent s'impliquent directement. Pendant environ sept semaines, le candidat devient le lien entre les événements de la scène nationale et le voteur. Tom Brook croit que notre système politique bénéficierait d'un retour à la démocratie de paliers. II n'a que d'éloges pour les campagnes de financement du Parti Québécois qu'il voit comme un exemple à suivre dans cette direction.

Getting Elected in Canada aurait toutefois bénéficié d'un plus grand souci du détail ainsi que d'autres sources que l'auteur pour corroborer ses arguments. À quelques reprises, le lecteur doit faire 
un acte de foi et croire Brook sans pouvoir vérifier la véracité de ses données. Par exemple, il soutient que reconnaître le nom du candidat est le facteur le plus important guidant la décision de l'électorat, sans toutefois identifier la source d'une telle déclaration. Plus loin, il note que plusieurs études ont démontré l'importance de certaines caractéristiques physiques telles que la taille et le poids dans le choix des voteurs, sans donner plus de précisions.

En somme, Brook réussit à diriger notre attention sur des individus qui sont trop souvent ignorés. Dans la mesure où ce livre se veut plus d'intérêt public qu'académique, l'auteur traite efficacement des particularités d'une campagne électorale dans une circonscription. Sans toutefois modifier le consensus sur le faible impact des candidats locaux dans la prise de décision de I'électorat, Tom Brook nous rappelle qu'en fin de compte, une élection consiste en un petit groupe d'individus essayant de convaincre un autre groupe d'individus.

André Turcotte 